\title{
Understanding the factors affecting e-business adoption and impact on \\ logistics processes
}

\author{
Aristides Matopoulos* \\ *Corresponding author: Department of Marketing and Operations Management, University of Macedonia, 156 \\ Egnatia st. 54006, Thessaloniki, Greece, Tel. +302310891728, Fax +302310891804, arismat@uom.gr \\ Maro Vlachopoulou \\ Department of Applied Informatics, University of Macedonia, 156 Egnatia st. 54006, Thessaloniki, Greece, Tel. \\ +302310891867, Fax+302310891804, mavla@uom.gr \\ Vicky Manthou \\ Department of Applied Informatics, University of Macedonia, 156 Egnatia st. 54006, Thessaloniki, Greece, Tel. \\ +302310891893, Fax+302310891804, manthou@uom.gr
}

\begin{abstract}
Purpose - To conceptualize e-business adoption and to generate understanding of the range of factors affecting the adoption process. The paper also aims at exploring the perceived impact of ebusiness adoption on logistics related processes.
\end{abstract}

Methodology - Case study research, by conducting in-depth interviews in eight companies.

Findings - E-business adoption is not exclusively a matter of resources. Increased e-business adoption and impact are caused by increased operational compatibility, as well as increased levels of collaboration. In terms of e-business impact this mainly refers to cycle time reductions and quality improvements, rather than direct cost reductions as reported by other authors.

Research limitations/implications - The intrinsic weakness of the research method and the way concepts were operationalized limits the ability to generalize findings.

Practical implications - Managers should emphasise developing their relationships with their suppliers/customers, in an effort to do common e-business investments, and should aim to increase their partners' commitment to the use of these applications.

Originality/value of the paper - This paper provides empirical evidence from a sector where limited research efforts have taken place. Explanations can be helpful to other researchers involved in the understanding of the adoption of e-business and its impact.

Keywords: e-business adoption, e-business impact, logistics processes, supply chains, agri-food industry

Paper type: Research paper

\section{Introduction}

The Information and Communication Technology revolution and the introduction of e-business applications in the mid nineties comprised an excellent opportunity for companies wishing to facilitate, improve, and even transform their business processes. However, much of the initial enthusiasm has turned to scepticism because companies are unable to quantify or even clarify the role and the real benefits of e-business. E-business applications provide a plethora of benefits such as 
improved information and data exchanges, facilitated business processes and consequently, improved coordination and significant cost reduction (De Boer et al., 2002; Croom, 2005). Despite the expected benefits, adoption rates in the food industry, in contrast to other sectors, have been rather low (E-business watch, 2007). This paper seeks the factors underlying and explaining low adoption of e-business. In addition, it explores the impact of e-business adoption on logistics processes in an industry specific context, since different industries present different characteristics that complicate analyses (Auramo, 2002). The paper focuses on the Greek agri-food industry, which is a very dynamic and competitive and one of the most important sector of the Greek economy. The aim is to generate understanding of the range of factors affecting e-business adoption in the agri-food industry, and in particular to explore the reasons for different levels of perceived e-business impact.

\section{A conceptual model for e-business adoption and impact}

One of the basic ideas of the conceptual model, which is presented in figure 1, is that e-business adoption and its impact is not strictly an intra-firm issue. This is due to the interactive nature of ebusiness applications. In this research, e-business adoption is related to the characteristics of ebusiness applications in coherence to the characteristics of the agri-food sector, as well as, those related to the relationships of supply chain members of the specific sector (analysis in section 2.2). Moreover, e-business is linked to the impact on company's logistics-related processes. The conceptual model, as well as the relationships between the concepts are described below and are deduced from empirical researches (Kwon and Zmud, 1987; Culkin and Smith, 2000; Martin and Matlay, 2001; Patterson et al. 2003, Wu et al. 2003).

Figure 1. The research model

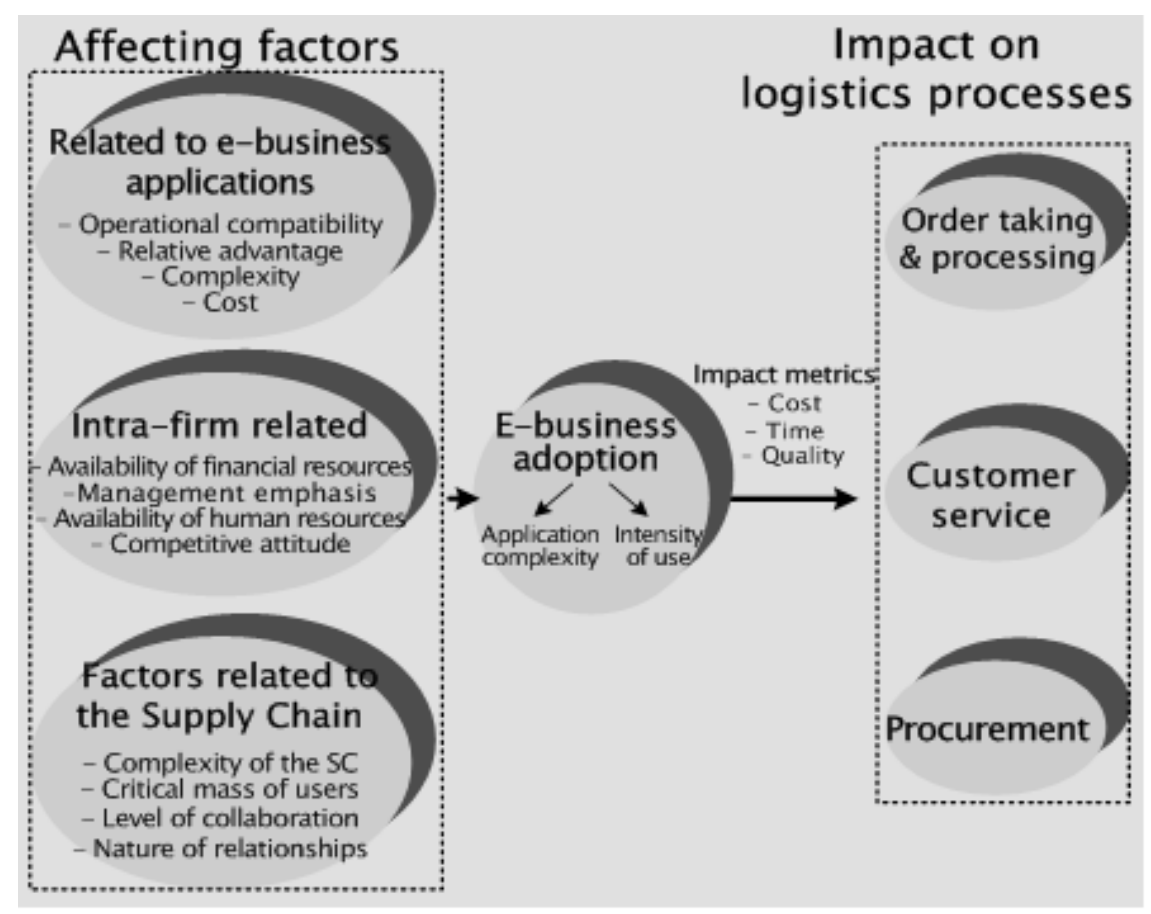

\subsection{Defining and operationalizing e-business}

The definition of e-business is still debated and the relevant literature offers a plethora of definitions and approaches. In some surveys e-commerce is perceived as an equivalent of e-business, ignoring the fact that e-business applications vary in complexity. In this paper, e-business is not approached as 
a single application, but rather as a term encompassing a number of applications varying from the very simple use of e-mail to more complex collaborative platforms (Brown and Lockett, 2004). Similarly, in an effort to avoid generalizations regarding the adoption of e-business the following dimensions are taken into account (Van der Veen, 2004):

- Activity: this means the way the company is supported by e-business, in terms of specific activities (e.g. purchase orders).

- Application: this means the use of certain e-business applications, which present specific level of complexity (e.g. e-business applications varying from very low complexity to very high complexity).

- Value creation: this means the value or the impact generated for the company as a result of the adoption of e-business.

- Intensity of use: this means the frequency of e-business use. In other words, very intense use of a specific e-business application indicates that the company is heavily relied on this application.

The focus in this research is on three of the more basic processes for every company: ordering (order taking and processing), customer service, and procurement. These processes capture many aspects of the supply chain of each company. For example, customer service is linked to upstream parts of the supply chain, ordering is related to internal operation of a company and finally procurement is linking the company with to the downstream part of the supply chain. In addition, in this research the complexity levels proposed by Locket and Brown (2001), are considered. Table 1 provides a classification of e-business application complexity.

Table 1. Classification of e-business application complexity (Source: Lockett and Brown, 2001)

\begin{tabular}{ll}
\hline Examples & Complexity \\
\hline E-Mail, Web access & Very low \\
Web site & Low \\
MS Office, Intranet & Low \\
Buying and Selling on-line & Medium \\
Extranet & Medium \\
Financials, SFA, vertical applications & High \\
E-marketplaces & High \\
ESCM, eCRM & Very high \\
Emerging platforms $^{\text {a }}$ & Very high \\
\hline
\end{tabular}

\subsection{Factors affecting the adoption of e- business applications}

\section{Factors related to the applications}

These factors refer to the appropriateness of e-business in specific business fields. According to the literature, the following factors have been recognized: operational compatibility, relative advantage, complexity and the cost of e-business applications.

- Operational compatibility deals with how compatible are the e-business applications with the existing activities of companies (Rogers, 1995). In the context of the food industry, operational compatibility could be affected by product and sector specific characteristics.

- Relative advantage refers to the expected benefits and the usefulness arising from e-business applications in comparison to other applications (Rogers, 1995).

- Complexity refers to the difficulties that a company is expected to face in understanding and using the applications (Van der Veen, 2004).

- Cost is linked to the perceptions of the persons interviewed regarding the capital needed for investments. In many cases, e-business applications, particularly very complicated ones, are very expensive. 
Intra-firm related factors

These factors are related to companies' characteristics, such as the availability of financial resources, the management emphasis put on adoption, the availability of human resources, and the competitive attitude of the company. The availability of financial resources, although linked to the cost of applications, is related with company's financial health. According to many authors this factor is critical (Fillies, 2002; Van Beverley and Thomson, 2002). For example, in the European food sector low ebusiness adoption rates have been linked to the size of companies, since the majority of companies operating in the sectors are Small and Medium Enterprises (SME's) characterized by limited availability of financial resources (E-business watch, 2007).

Another important factor is management emphasis in the adoption process, which is actually related to top managers' commitment. In many cases, particularly in SME's, these intra-firm factors become at least as important as every other factor (Fillies et al., 2003). The availability of human resources is associated with the existence of employees which have the knowledge and experience to use ebusiness applications (Mehrtens et al., 2001). Finally, competitive attitude is allied to company's perception regarding the way in which improvements in the competitive position of the company will be achieved as a result of the adoption of e-business applications (Waarts et al., 2002).

\section{Factors related to the supply chain}

These factors take into consideration companies' external environment. Supply chain complexity refers to the number of entities interacting with a particular company. In addition, it takes into account the number of suppliers, their proximity, as well as the complexity of transactions. Critical mass of users reflects the number and importance of supply chain partners that are using e-business applications (Markus, 1990). The level of collaboration is another important factor. Long-term relationships among organizations which are characterized by trust have proved that facilitate electronic integration (Konsynski and McFarlan, 1990). Trust is a crucial barrier towards the uptake of e-business applications that needs further attention specifically in the case of the food sector which is characterized by cross-country transactions and exchanges. The nature of relationships includes characteristics such as power and dependence. Many researches have shown that pressure from a company's environment (e.g. suppliers-customers) affects e-business adoption (Premkumar and Roberts, 1999; Mehrtens et al., 2001).

\subsection{Impact of e-business adoption on logistics processes}

Croom's (2005) research revealed that companies greatly acknowledge the benefits of using ebusiness in logistics processes. However, what seems to be missing in the literature is more focused research on the impact of e-business on specific processes with emphasis on specific performance dimensions (Cross, 2000; Ferrari, 2000). Johnson et al. (2007) argued that understanding of how and where firms use e-business and the direct benefits that they provide is still limited. This research relates the impact of e-business adoption to customer service, ordering (order-taking and processing) and procurement.

To assess the impact on these processes a combination of financial and non-financial measures, such as cost, time and quality, was used. The use of such measures provides a more complete view (Eccles 1998). Cost is one of the most useful and reliable measures for the assessment of changes to logistics processing (Chow et al., 1994). Similarly, time was included as it is a critical aspect in today's competition (Medori and Steeple, 2000). In this research, time refers to the time required to perform business processes. The research by Muilerman et al. (2005) in the Dutch food industry revealed that performance improvements were associated with time reductions in logistics processes. Regarding quality two dimensions were considered, reliability and flexibility (Duclos et al. 2003; Krauth et al. 2005). 


\section{Research Methodology}

\subsection{Case selection and description}

This research enters into three major areas, namely: information and communication technologies (where e-business in included), logistics and the agri-food industry. Case study research has been lately recognised as an increasingly important type of research in each one of these three areas, since it enables a more descriptive and exploratory approach (Yin, 1994; Sterns et al. 1998; Myers and Avison, 2002; Mangan et al. 2004).

Eight companies from the agri-food sector were selected. The companies agreed to take part in the research provided that confidentiality was assured. Firms are identified as firm 1 to 8 . Firms 1,2 and 3 are three of the biggest retailers in Greece. In particular, firms 1 and 3 are the Greek branches of multinational retailers, while firm 2 is domestic. Firm 4, is the Greek part of a multinational dairy company; firm 5 is a domestic company that is supplying food products (burgers, salads etc) to the biggest fast food chain restaurant in Greece. Finally, firms 6 and 7 operate in the fruit canning industry, while firm 8 is one of the biggest wholesalers of fresh produce in Greece. Table 2 presents a brief description of the companies and their general characteristics.

Table 2. An overview of the companies

\begin{tabular}{llcccl}
\hline Firm & Sub-sector & Turnover (million $€$ ) & Number of employees & Number of interviewees & Interviewees \\
\hline 1 & Retailer & 400 & 2500 & 2 & $\begin{array}{l}\text { Logistics manager } \\
\text { IT manager } \\
\text { Logistics manager } \\
\text { IT manager }\end{array}$ \\
2 & Retailer & 450 & 2500 & 3 & $\begin{array}{l}\text { Purchasing manager } \\
\text { Logistics manager }\end{array}$ \\
3 & Retailer & 1750 & 3200 & 2 & $\begin{array}{l}\text { IT manager } \\
\text { Finance Director } \\
\text { Logistics Manager }\end{array}$ \\
4 & Manufacturer & 425 & 150 & 3 & $\begin{array}{l}\text { IT manager } \\
\text { Ifogistics director } \\
\text { Purchasing manager } \\
\text { IT manager }\end{array}$ \\
5 & Manufacturer & 75 & 380 & 3 & $\begin{array}{l}\text { CEO } \\
\text { Finance manager } \\
\text { IT manager } \\
\text { CEO }\end{array}$ \\
7 & Manufacturer & 22 & $36(500$ seasonal) & 3 & $\begin{array}{l}\text { Finance director } \\
\text { Purchasing manager } \\
\text { IT manager }\end{array}$ \\
\hline
\end{tabular}

\subsection{Data collection}

Initially, a case study protocol was developed based on the conceptual framework. The protocol was used to guide the semi-structured in-depth interviews and data collection (Yin, 1994). A pilot study used to review the research propositions improved the conceptual understanding of the research issues. Twenty interviews were conducted each taking 1-1.5 hours. All interviews were tape recorded worth the consent of the interviewee and, prior to each interview, the research agenda was explained. To enhance the reliability and validity of this study, data collection drew on various sources such as, interviews, direct observation and documentation.

Most of the data collected were qualitative, however, quantitative data (e.g. cost and time improvements, errors' reduction) based on managers' assessment were also collected. For this kind of data a five-point perceptual interval scale ranging from 1 (means there is no impact on logistics 
processes) to 5 (extensive- it means there is an extensive impact) was used, so as to allow respondents to report the perceived impact of e-business on logistics processes. In order to measure the impact of e-business applications the dimension of the Intensity of use (see 2.1) was used (Van der Veen, 2004). When managers had difficulties in directly assessing the impact of e-business they were asked to indicate their level of reliance on the specific applications, as well as the expected potential implications if the applications were not used.

\section{Empirical results}

\subsection{E-business adoption and impact}

Table 3 presents an overview of companies' responses regarding e-business adoption. The symbol $(\mathrm{V})$ and $(X)$ are used to state the adoption or not of a specific application, respectively. Next, (after the slash symbol) follows the results regarding the intensity of use of each application, where the following symbols of ranking are used: not at all (1), low (2), medium (3), high (4), extensive (5). In case where neither adoption (X) nor impact (1) is reported, the NA (not applicable) symbol is used.

Table 3. An overview of companies' responses regarding e-business adoption

\begin{tabular}{lcccccccc}
\hline E-business applications & \multicolumn{7}{c}{ Adoption } \\
& Firm 1 & Firm 2 & Firm 3 & Firm 4 & Firm 5 & Firm 6 & Firm 7 & Firm 8 \\
\hline Internet access & $\mathrm{V} / 5$ & $\mathrm{~V} / 5$ & $\mathrm{~V} / 5$ & $\mathrm{~V} / 5$ & $\mathrm{~V} / 5$ & $\mathrm{~V} / 5$ & $\mathrm{~V} / 5$ & $\mathrm{~V} / 5$ \\
E-mail & $\mathrm{V} / 5$ & $\mathrm{~V} / 5$ & $\mathrm{~V} / 5$ & $\mathrm{~V} / 3$ & $\mathrm{~V} / 2$ & $\mathrm{~V} / 5$ & $\mathrm{~V} / 5$ & $\mathrm{~V} / 3$ \\
Website & $\mathrm{NA}$ & $\mathrm{V} / 1$ & $\mathrm{~V} / 3$ & $\mathrm{~V} / 2$ & $\mathrm{~V} / 2$ & $\mathrm{~V} / 5$ & $\mathrm{~V} / 3$ & $\mathrm{~V} / 2$ \\
Intranet & $\mathrm{V} / 5$ & $\mathrm{~V} / 5$ & $\mathrm{~V} / 5$ & $\mathrm{~V} / 5$ & $\mathrm{~V} / 5$ & $\mathrm{~V} / 5$ & $\mathrm{~V} / 5$ & $\mathrm{~V} / 5$ \\
Selling-buying online & $\mathrm{NA}$ & $\mathrm{NA}$ & $\mathrm{NA}$ & $\mathrm{NA}$ & $\mathrm{NA}$ & $\mathrm{V} / 4$ & $\mathrm{NA}$ & $\mathrm{NA}$ \\
Extranet & $\mathrm{X} / 2$ & $\mathrm{X} / 2$ & $\mathrm{~V} / 5$ & $\mathrm{NA}$ & $\mathrm{NA}$ & $\mathrm{NA}$ & $\mathrm{NA}$ & $\mathrm{NA}$ \\
E-banking & $\mathrm{V} / 4$ & $\mathrm{X} / 2$ & $\mathrm{X} / 2$ & $\mathrm{NA}$ & $\mathrm{NA}$ & $\mathrm{V} / 4$ & $\mathrm{NA}$ & $\mathrm{NA}$ \\
E-marketplace & $\mathrm{NA}$ & $\mathrm{NA}$ & $\mathrm{NA}$ & $\mathrm{NA}$ & $\mathrm{NA}$ & $\mathrm{NA}$ & $\mathrm{NA}$ & $\mathrm{NA}$ \\
E-SCM, E-CRM & $\mathrm{NA}$ & $\mathrm{NA}$ & $\mathrm{NA}$ & $\mathrm{NA}$ & $\mathrm{NA}$ & $\mathrm{NA}$ & $\mathrm{NA}$ & $\mathrm{NA}$ \\
Collaborative platforms & $\mathrm{V} / 4$ & $\mathrm{~V} / 5$ & $\mathrm{~V} / 5$ & $\mathrm{NA}$ & $\mathrm{NA}$ & $\mathrm{NA}$ & $\mathrm{NA}$ & NA \\
\hline
\end{tabular}

Table 4 gives an overview of companies' responses regarding e-business impact per firm for several processes and key dimensions of each process. A five point scale was used anchored by 1: no impact and 5: extensive impact. A more detailed analysis follows.

Table 4. Overall impact of e-business adoption on logistics processes

\begin{tabular}{lcccccccccc}
\hline & Dimension & \multicolumn{7}{c}{ Impact } \\
& & Firm 1 & Firm 2 & Firm 3 & Firm 4 & Firm 5 & Firm 6 & Firm 7 & Firm 8 \\
\hline Customer Service & Cost & 3 & 3 & 3 & 2 & 1 & 2 & 1 & 1 \\
& Time & 4 & 3 & 5 & 3 & 4 & 3 & 2 & 2 \\
& Quality & 4 & 4 & 5 & 3 & 4 & 4 & 3 & 1 \\
& Average & $\mathbf{3 , 7}$ & $\mathbf{3 , 3}$ & $\mathbf{4 , 3}$ & $\mathbf{2 , 7}$ & $\mathbf{3}$ & $\mathbf{2}$ & $\mathbf{2}$ & $\mathbf{1 , 3}$ \\
\hline
\end{tabular}




\begin{tabular}{|c|c|c|c|c|c|c|c|c|c|}
\hline \multirow[t]{4}{*}{ Order taking - Processing } & Cost & 3 & 3 & 3 & 2 & 3 & 1 & 1 & 1 \\
\hline & Time & 5 & 5 & 5 & 3 & 4 & 2 & 2 & 2 \\
\hline & Quality & 5 & 5 & 5 & 3 & 4 & 2 & 2 & 1 \\
\hline & Average & 4,3 & 4,3 & 4,3 & 2,7 & 3.7 & 1.7 & 1.7 & 1.3 \\
\hline \multirow[t]{4}{*}{ Procurement } & Cost & 2 & 3 & 3 & 1 & 1 & 1 & 1 & 1 \\
\hline & Time & 4 & 4 & 4 & 1 & 2 & 2 & 2 & 1 \\
\hline & Quality & 4 & 4 & 4 & 1 & 2 & 3 & 2 & 1 \\
\hline & Average & 3,3 & 3,7 & 3,7 & 1 & 1.7 & 2 & 1,7 & 1 \\
\hline Average & & 3,7 & 3,7 & 4,1 & 2,1 & 2,8 & 1,9 & 1,8 & 1,2 \\
\hline
\end{tabular}

*Based on information (manager's estimations) collected from the case studies.

The impact of e-business on firms 1 and 2 is rather high and refers primarily to order taking and processing; less to customer service and procurement. Particularly for ordering, according to the logistics director of Firm 1: "it is not possible to think a different way for ordering; the way we deal with ordering is a basic part of our internal functioning". Improvement in these processes is mainly related to time reductions and quality. The impact of e-business on logistics process on firm 3 refers to the ordering process and customer service. In specific, interviewees reported improvements in terms of quality and time reductions. In firms 4 and 5, e-business impact refers mainly to ordering and customer service. Improvements in these processes for both companies are related to time reductions and quality melioration. In firm 6, e-business impact is low on average. Regarding, performance it seems that the perceived impact is linked more to time and quality and less to cost. Finally, the impact on firms 7 and 8 is low and the customer service process seems to be more affected than ordering and procurement.

\subsection{Analysis of the factors affecting e-business adoption and impact}

The first stage of the analysis involved the depiction of companies in relation to e-business adoption and impact by using a five-point scale anchored by 1: no impact-5: extensive impact. In order to further to validate and support these results a hierarchical cluster analysis was conducted using the Ward method (Ward, 1963). The analysis identified two major clusters labelled A and B (Figure 2). Having identified these two clusters, the next step of the analysis was to understand the factors influencing e-business adoption and impact, as well as to understand companies' existing differences between and within the clusters. The analysis was based on the expressed levels of e-business adoption and impact and the companies' responses regarding affecting factors as those proposed in the framework.

Figure 2. A depiction of companies and of the clusters identified 


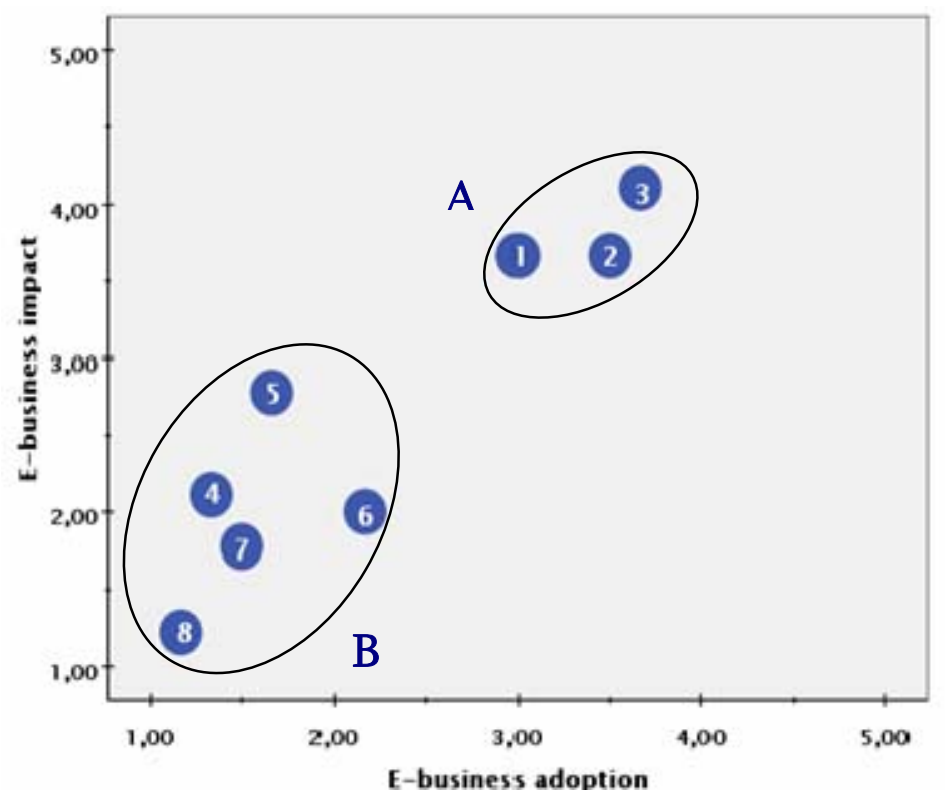

\subsubsection{Factors related to e-business applications}

Companies reporting greater levels of e-business adoption and impact (A1-A2-A3) present also greater operational compatibility. Contrastingly, in firms B6-B7-B8 the specific characteristics of products hinder the integration of e-business applications in the way companies do business. The IT manager from firm 6 stated: "not all applications fit to our business; more applicable seem to be those related to information exchanges and not more complex applications-even if we had these applications we wouldn't be able to benefit". Production for these companies takes place between May and September, while sale orders are placed 1-2 times per year, thus reducing the frequency of transactions. Regarding the relative advantage for the three retailers (A1-A2-A3), the usefulness of ebusiness applications is not questioned even for low complexity applications. The logistics director of firm 1 stated for example that: "no one can imagine the operation of their sectors without the use of these applications; it is just impossible". The relative advantage for these companies is even higher for highly complex applications. Complexity is not a problem for companies although in some cases (B4B5-B7) it was clear that there was an important lack of understanding. The perception of companies regarding the cost of applications does not drastically diversify. For example, for most companies (A1A2-A3-B4-B5-B6-B7), irrespectively of the level of e-business adoption, the cost of applications has not been reported as a constraint.

\subsubsection{Intra-firm related factors}

Lack of financial resources was not mentioned as a significant constraint to e-business adoption. A manager from firm 5, argued that: "adopting e-business nowadays is not really a matter of money, time or personnel. These factors are just an excuse for small companies in an effort to avoid changing their way of doing business". Management emphasis seems insignificant in companies with lower adoption rates (B4-B5-B6-B7-B8). This situation is much more intense for some companies (B6-B7-B8) with more market power. Concerning human resources' availability, lack of knowledge has not been mentioned as an important factor affecting e-business adoption. Even smaller companies (B6-B7-B8), had departments where people with an IT background and knowledge were in charge. Finally, these companies that are competition sensitive and are competition oriented (A1-A2-A3) are more sensitive when it comes to technology and e-business adoption. 


\subsubsection{Supply Chain related factors}

Companies with more complex supply chain indicate increased e-business adoption rates. For example, retailer $A 1$ has a supplier base comprising approximately 300 suppliers (40\% from abroad- only $6 \%$ local) and 363 retail outlets. In that aspect, synchronization requirements are greater than in firms from cluster B. Regarding the lack of critical mass of users, it is a problem for both clusters, particularly when it comes to more complex applications. In a recent letter sent by firm A1, to its entire supplier base, in an effort to prepare EDI adoption, only five percent of the suppliers responded. All companies agreed that increased levels of collaboration affect positively e-business adoption. Companies presenting higher adoption rates (A1-A2-A3) are characterized by closer collaboration with some of their suppliers. For example, retailers $A 1$ and $A 2$, were shortly going to implement a more complex ebusiness application (web-based EDI) together with one key manufacturer and one key wholesaler. Concerning the nature of relationships, although some companies (A1-A2-A3) are able to put pressure on their suppliers, they do not follow this strategy. The logistics manager from firm A3 argued that "In the current phase no one in the market is in the position to impose e-business adoption even to the weakest companies".

\subsection{Grouping and identifying common attributes between firms and factors}

The analysis of the case studies has led in the identification of patterns of factors, that differently effect the adoption and the impact of e-business applications. Four different categories have been distinguished. Figure 3 presents these categories.

Figure 3. The role of factors on the adoption and impact of e-business

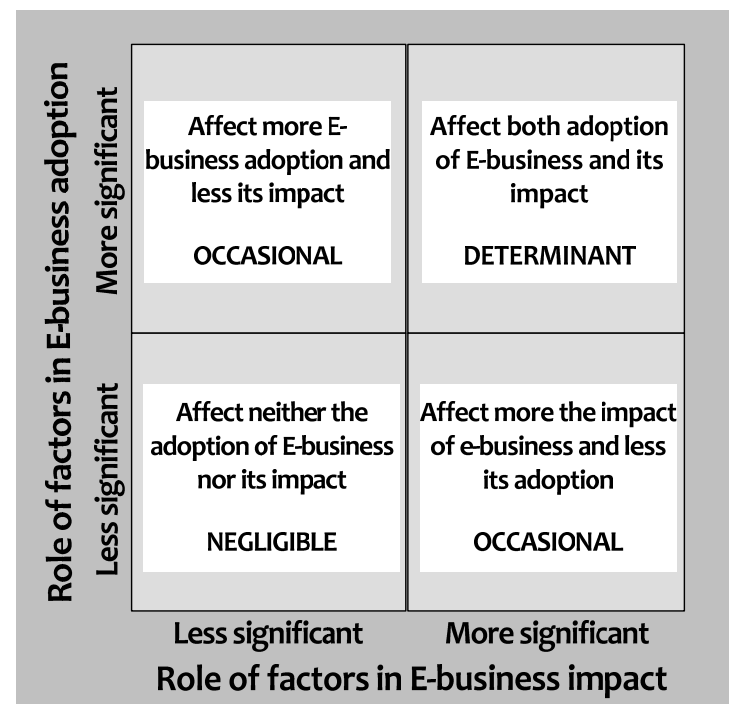

The analysis has shown that operational compatibility and the level of collaboration are two of the factors that play a determinant role in the adoption of e-business and its impact. The evidence collected for these factors justify the existence of the two clusters. For example, both factors exist in the case of companies $A_{1}, A_{2}$ and $A_{3}$, while only one of the factors appears as in the case of companies $\mathrm{B} 4, \mathrm{~B} 5$ and $\mathrm{B} 6$, or none as in the case of $\mathrm{B} 7$ and $\mathrm{B} 8$.

Concerning occasional factors, relative advantage in particular, research results are consistent with earlier work by Mehrtens et al. (2001) and Grandon and Pearson, (2004), by explaining to a great extent why some companies are still using old communication applications instead of e-business applications. 
Finally, the role of some factors such as cost, application complexity, availability of financial and human resources, and the nature of relationships do not seem to be important. Even in smaller companies, none of these factors seems to play an important role. For example, the role of financial and human resources availability is negligible. The findings concur also with the findings of Caldeira and Ward (2003) regarding the adoption of IS/IT systems in Portuguese small-medium sized enterprises. Table 6 presents a grouping of these factors.

Table 6. Classification of factors which are linked to the adoption and impact of e-business

\begin{tabular}{llll}
\hline Factors & Determinant & Occasional & Negligible \\
\hline 1. E-business Applications & Operational compatibility & Relative advantage & $\begin{array}{l}\text { Complexity } \\
\text { Cost }\end{array}$ \\
\hline 2. Intra-firm & & $\begin{array}{l}\text { Management emphasis } \\
\text { Competitive attitude }\end{array}$ & $\begin{array}{l}\text { Availability of financial resources } \\
\text { Availability of human resources }\end{array}$ \\
\hline 3. Supply chain & Level of collaboration & $\begin{array}{l}\text { Complexity of the SC } \\
\text { Critical mass of users }\end{array}$ & Nature of relationships \\
\hline
\end{tabular}

\section{Conclusions}

The literature review pertaining to e-business adoption revealed that e-business is often wrongly considered as one single application and its adoption nothing but an internal issue for companies. Also, past studies of e-business have focused more on identifying the expected benefits, rather than on assessing the exact impact of the adoption. Against this background, the first step of this research was to operationalize the e-business concept so as to facilitate assessing its impact. In particular, specific logistics activities and also a specific business sector were selected so as to avoid generalizations. The factors associated with e-business adoption and impact were identified from the literature, and their role was assessed by using case study research.

An important research finding is that the impact of e-business on logistics processes mainly refers to time reductions and quality improvements, rather than cost reductions as reported by many authors (Croom 2000, De Boer et al. 2002). The old view that e-business applications are associated with cost reductions is contested in this research. We found that companies are more likely to realize improvements in cycle time reductions and process quality.

In terms of e-business adoption, this study found that Greek agri-food companies have not adopted more complicated e-business applications, since none of the major players in the industry has ever asked for it so far. Only companies that are competition-sensitive seem to follow the developments. From the case studies it is also clear that the adoption of e-business applications is not exclusively a matter of resources. On the contrary, operational compatibility and the level of collaboration are two of the factors that play a determinant role in increased e-business adoption and impact.

Subsequently, managers and practitioners should be prepared to put emphasis on developing their relationships with their suppliers/customers preparatory to implementing common e-business investments. In addition, they should try to increase partners' commitment to using these applications. As case studies revealed, increased impact on logistics processes results from higher intensity of use and not necessarily from the adoption of more complex applications. Managers should therefore try to integrate e-business applications in their daily operations, making e-business part of their "modus operandi".

In terms of research limitations, several constraints limit this research's applicability. Many of these are related to the intrinsic weakness of the selected research method, which limits the ability to generalise the findings. Additional limitations refer to the way concepts were operationalized in this research. For example, e-business adoption was operationalized by using two variables (application complexity and intensity of use) while more or different variables could be taken into consideration. 
In addition, the three specific measures used for the assessment of e-business impact were assumed to be of equal importance. Constraints also exist with reference to the research being undertaken in one country. Other studies (Chau et al. 2000, Markus et al. 2002) have shown that culture is linked to the ICT adoption and therefore the results may not be applicable to other countries. For example, the proposed classification of the factors may present differences in other countries. Finally, this research focused on medium to very large companies. It would be very interesting to evaluate the proposed model in small enterprises also and identify whether and in what way the role of the proposed factors is altered. Future research should emphasize on studying the impact of e-business adoption on other logistics processes.

\section{References}

Auramo, J., Aminoff, A. and Punakivi, M. (2002), "Research agenda for e-business logistics based on professional opinions", International Journal of Physical Distribution and Logistics Management, Vol. 32 No. 7, pp. 513-531.

Caldeira, M. M. and Ward, J. M. (2003), "Using resource-based theory to interpret the successful adoption and use of information systems and technology in manufacturing small and medium-sized enterprises", European Journal of Information Systems, Vol. 12, pp. 127-141.

Chau, P.Y.K., Cole, M. P., Massey, A., Montoya-Weiss, M. and O' Keefe, R. M. (2000), "Cultural differences in the Online Behaviour of Consumers", Communication of ACM, Vol. 45 No. 10, pp. 138-143.

Chow, G., Heavers, T.D. and Henriksson, L.E. (1994), "Logistics performance: definition and measurement", International Journal of Physical Distribution and Logistics Management, Vol. 24 No. 1, pp. 17-28.

Croom, S.R. (2005), "The impact of e-business on supply chain management", International Journal of Operations and Production Management, Vol. 25 No. 1, pp. 55-73.

Cross, G.J. (2000), "How e-business is transforming supply chain management", The Journal of Business Strategy, Vol. 21 No. 2, pp. 36-39.

Culkin N. and Smith, D. (2000), "An emotional business: a guide to understanding the motivations of small business decision takers", Qualitative Market Research: An International Journal, Vol. 3 No. 3, pp. 145-157.

DeBoer, L., Harink, J. and Heijboer, G. (2002), "A conceptual model for assessing the impact of electronic procurement", European Journal of Purchasing and Supply Management, Vol. 8 No. 1, pp. 25-33.

E-business watch, (2007), "The European e-Business Report, A portrait of e-business in 10 sectors of the EU economy $5^{\text {th }}$ Synthesis Report of the e-Business Watch", European Commission, Enterprise Directorate-General e-Business, ICT Industries and Services, January 2007.

Eccles, R. (1998), "The performance measurement manifesto", In Harvard Business Review on Measuring Corporate Performance, Harvard Business School Press: Boston, MA, pp. 25-46.

Ferrari, R. (2000), "White paper frontline supply chain managers struggle with e-business", September, Richmond Events and AMR Research White Paper: New York.

Fillis, I., Johansson, U. and Wagner, B.A. (2003), "A conceptualization of the opportunities and barriers to e-business development in the smaller firm", Journal of Small Business and Enterprise Development, Vol. 10 No. 3, pp. 336-344.

Grandon, E. and Pearson, J. (2004), "Electronic commerce adoption: an empirical study of small and medium US businesses", Information and Management, Vol. 42, pp. 197-216.

Johnson, P.F., Klassen, R. D., Leenders, M. R. and Awayshehet, A. (2007), "Utilizing e-business technologies in supply chains: The impact of firm characteristics and teams", Journal of Operations Management, Vol. 25 No. 6, pp. 1255-1274. 
Konsynski, B.R. and McFarlan, W.F. (1990), "Information partnerships - shared data, shared scale", Harvard Business Review, Vol. 68 No. 5, pp. 114-120.

Krauth, E., Moonen, H., Popova, V. and Schut, M. (2005), "Understanding performance measurement and control in third party logistics", In Proceedings of the $13^{\text {th }}$ European Conference on Information Systems, 26-28 May, Regensburg.

Kwon, T.H. and Zmud, R.W. (1987), "Unifying the fragmented models of information systems implementation", In: Boland, R.J., Hirschheim, R.A., (eds.), Critical Issues in Information Systems Research, John Wiley: New York, pp. 247- 252.

Locket, N. and Brown, D.H. (2001), "A framework for the engagement of SME's in e-business", In Proceedings of the Americas Conference on Information Systems, Boston, MA, pp. 656-662.

Mangan, J., Lalwani, C. and Gardner, B. (2004), "Combining quantitative and qualitative methodologies in logistics research", International Journal of Physical Distribution and Logistics Management, Vol. 34 No. 7, pp. 565-578.

Markus, M.L., Petrie, D. and Axline, S. (2002), "Bucking the trends: what the future may hold for ERP packages", Information System Frontiers, Vol. 2 No. 2, pp. 181-193.

Martin L. M. and Matlay H. (2001), "Blanket approaches to promoting ICT in small firms: Some lessons from the DTI ladder adoption model in the UK", Internet Research: Electronic Networking Applications and Policy, Vol. 11 No. 5, pp. $399-410$.

Medori, D. and Steeple, D. (2000), "A framework for auditing and enhancing performance measurement systems", International Journal of Operations and Production Management, Vol. 20 No. 5, pp. 520-533.

Mehrtens, J., Cragg, P.B. and Mills, A.M. (2001), "A model of Internet adoption by SME's", Information and Management, Vol. 38, pp. 165-176.

Muilerman, G.J., Van der Hoorn, T. and Van der Heijden, R. (2005), "Determining the impacts of timebased logistics strategies in the Dutch food industry", International Journal of Logistics: Research and Applications, Vol. 8 No. 3, pp. 237-247.

Myers, M.D. and Avison, D.E. (2002), Qualitative Research in Information Systems: A Reader, Sage Publications, London, UK.

Patterson, K.A., Grimm, C.M. and Corsi, T.M. (2003), "Adopting new technologies for supply chain management", Transportation Research Part E, Vol. 39, pp. 95-121.

Premkumar, G. and Roberts, M. (1999), "Adoption of new information technologies in rural small businesses", Omega: The International Journal of Management Science, Vol. 27 No. 4, pp. 467-484.

Rogers, E. M. (1995), Diffusion of Innovations, The Free Press, New York, NY.

Sterns, J. A., Schweikhardt, D.B. and Peterson, H.C. (1998), "Using case studies as an approach for conducting agribusiness research", International Food and Agribusiness Management Review, Vol. 1 No. 3, pp. 311-327.

Van der Veen, M. (2004), Explaining e-business adoption: innovation and entrepreneurship in Dutch SME's, PhD Thesis, University of Twente, The Netherlands.

Waarts, E., Van Everdingen, Y.M. and Van Hillegersberg, J. (2002), "The dynamics of factors affecting the adoption of innovations", The Journal of Product Innovation Management, Vol. 19 No. 6, pp. 412-423.

Ward, J. H. (1963), "Hierachical grouping to optimize an objective function", Journal of American Statistic Association, Vol. 58, pp. 236-244.

Wu, F., Mahajan, V. and Balasubramanian, S. (2003), "An analysis of e-business adoption and its impact on business performance", Journal of the Academy of Marketing Science, Vol. 31 No. 4, pp. 425-447. Yin, R. (1994), Case study research: Design and Methods, $2^{\text {nd }}$ edition, Sage Publications, Thousand Oaks. 